\title{
Yield and Quality of Caprine Oocytes by using Aspiration Method
}

\author{
M. Sundara Vinayaki* \\ Department of Veterinary Physiology and Biochemistry, \\ Veterinary College and Research Institute, Tirunelveli-627 358, India \\ TamilNadu Veterinary and Animal Sciences University, India \\ *Corresponding author
}

\section{A B S T R A C T}

Keywords

Caprine, Oocytes, Stereomicroscope, Aspiration

Article Info

Accepted:

26 May 2020

Available Online:

10 June 2020
The efficiency of Oocyte collection by aspiration method was assessed. A sum of 980 caprine ovaries were collected from local abattoir and used for the present study. Out of these ovaries a total of 3243 oocytes were collected. Out of which 2254 culturable oocytes were selected under stereomicroscope. The total number of oocytes and culturable oocytes recovered per ovary were 3.2 and 2.4 respectively $30 \%$ of the total population comprised fully and partially denuded oocytes which were not used. Aspiration yielded significantly higher number of Oocytes per ovary. It was found that aspiration method also used for collection oocytes form ovaries.

\section{Introduction}

Embryo production in both in vivo and in vitro methods can make increased assurance in recreating life without any major loss of time. E.T is an area of reproductive physiology which has excited the imagination of researchers, farmers and public alike because of its exiting multiple applications in world animal production. In case of goat, higher number of embryos could be I.V.M.F.C. But large numbers of oocytes are required for I.V.M.F.C. Therefore success of these techniques in goat production depends on the continuous supply of the quality oocytes in optimum quantity. Surgical or laparoscopic methods are very expensive and also recovered per ovary is very small. So this study was undertaken to identify the Yield and quality of caprine Oocytes by using aspiration method.

\section{Materials and Methods}

\section{Collections of ovaries}

Ovaries from matured goats were collected from local abattoir in Sterile Normal Saline 
solution (NSS 0.85\%) supplemented with antibiotics (penicillin100 IU/ml, streptomycin $50 \mu \mathrm{g} / \mathrm{ml}$ ) and antimycotics (Amphotericin $2.5 \mathrm{mg} / \mathrm{L}$ ) at $30-35^{\circ} \mathrm{C}$ in an isothermic container and transported to laboratory within $2 \mathrm{~h}$ of slaughter.

\section{Oocyte collections}

Oocytes isolated from follicular fluid graded and thawed as per the technique of Taru et al., (1996). The surrounding tissues were trimmed off and the ovaries were washed several times with sterile NSS. The ovaries were than exposed to $70 \%$ ethyl alcohol for 30 seconds and finally washed in $\mathrm{m}$ DPBS

Oocytes from surface follicle ( $>4 \mathrm{~mm}$ ) of goat ovaries were collected by puncturing the follicles with 18 gauge needle in a petridish containing OCM. Morphologically culturable oocytes i.e. those having compact, multilayered cumulus oocyte complexes (COCs) and evenly granulated cytoplasm were selected under a stereomicroscope (Bausch and Lomb) and transferred to another petridish containing OCM followed by 5 washings in oocyte washing media and finally washing in maturations medium.

\section{Results and Discussion}

A sum of 980 caprine ovaries were collected from local abattoir and used for the present study. Out of these ovaries a total of 3243 oocytes were collected. Out of which 2254 culturable oocytes were selected under stereomicroscope. The total number of oocytes and culturable oocytes recovered per ovary were 3.2 and 2.4 respectively (Table 1 , Fig 1). $30 \%$ of the total population comprised fully and partially denuded oocytes which were not included in this study.

Yield of culturable quality oocytes was highest with aspiration. This finding is in agreement with the results of Vijayakumaran (1995), Kharche et al., (2006) and Wang et al., (2007), Pawshe et al., (1994) obtained a comparatively lower percentage of culturable oocytes by puncture than the present study. But by sliciding method low yield may be due to the damage caused by the blade.

Many factors have been found to affect the yield and quality of oocytes viz, breed, season, time interval from collection of ovaries to oocyte harvest, temperature of media for transport of ovaries, retrieval technique and the criteria used for classification Rahman et al., (2008). This study revealed that yield of culturable quality oocytes was significantly higher by aspiration method so this aspiration method may be used for I.V.M.F.C techniques for collecting oocytes.

Table.1 Number of harvested and culturable oocytes obtained from caprine ovaries

\begin{tabular}{|l|c|c|}
\hline Total number of ovaries & $\begin{array}{c}\text { Total number of oocytes } \\
\text { harvested }\end{array}$ & $\begin{array}{c}\text { Total number of culturable } \\
\text { Oocytes recovered }\end{array}$ \\
\hline 980 & 3243 & 2254 \\
\hline
\end{tabular}

Number of oocytes/ovary: 3.2

Number of culturable oocytes/ovary: 2.4 


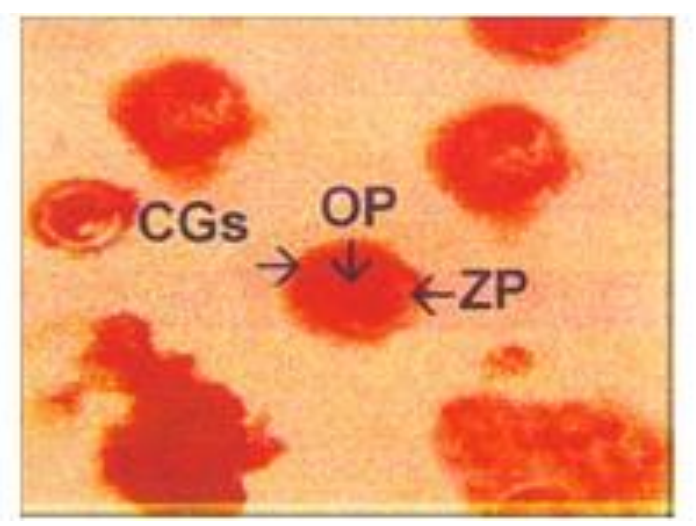

Fig.1 Culturable quality oocytes with compact cumulus granulose cells (CGS) distinct zona pellucida (ZP) and very evenly granulated ooplasm

It could be concluded from the present study that yield of culturable quality oocytes was significantly higher by aspiration method so this aspiration method may be used for I.V.M.F.C techniques for collecting oocytes in caprines.

\section{References}

Kharche, S.D., Goel, A.K., Jindal, S. K. and Sinha, N.K, 2006. In vitro maturation of caprine oocytes in different concentration of estrus goat serum. Small Rumi. Res. 64:186-189

Pawshe, C.H., Totey, S. M. and Jain, S.K. 1994.A comparison of three methods of recovery of goat oocytes for in vitro maturation and fertilization. Theriogenology. 42:117-125

Rahman, A.N.M.A., Abdullah, R.B. and Wan-Khadijah, W. E. 2008. Recovery and grading of goat oocytes with special reference to laparoscopic ovum pick-up technique: A review. Bacteriology, 7:612-622

Sharma, G.T., Majumdar, A.C and Bonde, S.W. (1996). Chronology of maturational events in goat oocytes cultured in vitro. Small Ruminant Research 22:25-30

Vijayakumaran, V. 1995. Effect of follicular size on in vitro maturation of goat oocytes. Ph.D., thesis. Tamil Nadu Veterinary and animal Sciences University, Madras, P. 185.

Wang, Z.G., Xu, Z.R. and Yu, S. 2007. Effects of Oocyte collection techniques and maturation media on in vitro maturation and subsequent embryo development in Boer Goat. Czech. Anim. Sci. 52:21-25

\section{How to cite this article:}

Sundara Vinayaki, M. 2020. Yield and Quality of Caprine Oocytes by using Aspiration Method. Int.J.Curr.Microbiol.App.Sci. 9(06): 3683-3685.

doi: https://doi.org/10.20546/ijcmas.2020.906.434 